\title{
Serum Zinc Level In Children With Acute Diarrheal Disease
}

Prof. Manal Anwar El-Hawary, Dr . Sherin Khamis Hussein , Dr.Noha Khalifa Abd Elghaffar and Rasha Ahmed Ibrahim Khalil

Pediatric department, clinical pathology department, faculty of medicine, fayoum university, Egypt.

\begin{abstract}
Background: Acute diarrhea remains a leading cause of death among infants and young children in low income countries. Zinc deficiency is associated with an increased risk of gastrointestinal infections, adverse effects on the structure and function of the gastrointestinal tract, and impaired immune function.
\end{abstract}

Aim of the work: Our aim of work is to determine the role of Zinc as a risk factor in the development of acute diarrhea in children.

Methods: Ninety children with acute diarrhea and eighty age-matched controls were enrolled. All of them were subjected to complete blood picture, stool analysis, serum Zinc level and serum electrolyte (for cases only).

Results: When comparing the mean serum zinc level among cases and controls there was no statistically significant difference found.

There was statistically significant difference between cases and controls as regards to hemoglobin level and TLC.

Stool analysis showed combined infection of ameba and oxyuris infections in 30\% of cases in contrast to16.3\% of controls .Also amebiasis was found in $54.4 \%$ of our cases and $37.5 \%$ of the control group.

A significant association was found between mean serum zinc level and serum sodium level; high mean serum zinc level was noticed in patients with low serum sodium level. There was no correlation between mean serum zinc level and patient's age, their anthropometric measures, frequency of diarrhea, and time of weaning, hemoglobin level, serum $\mathrm{Na}$ level and serum $\mathrm{K}$.

Key Words: Zinc, Diarrhea, Dehydration, Children

\section{INTRODUCTION}

Acute diarrhea remains the leading cause of death among infants and young 
children in low income countries (Bryce etal. ,2005)

Every year more than a million children less than five years of age succumb to the fluid loss and dehydration associated with the majority of diarrhea related deaths

\section{( Mathers etal.,2007)}

\section{In2008 the WHO formed an estimation}

of child mortality due to diarrhea in developing countries. In Egypt proportion of diarrhea death in children under five death is $47.7 \%$ in 1980

\section{(Boschi etal.,2008)}

The scientific community, over the past four decades, established a consensus on the most effective measures to reduce the incidence, morbidity, and mortality of acute diarrheal disease (Assis etal.,2013).

Exclusive breastfeeding for at least 6 months and supplemented up to 2 years of age has a significant impact in reducing the disease incidence and severity. In the field of biomedicine, the development of a vaccine against rotavirus and universal vaccine coverage are important contributions that have an impact on acute diarrheal disease incidence, by decreasing the severe forms and the number of hospitalizations, thus reducing the risk of death (UNICEF.,2009).

Most studies were conducted in poor regions and recruited children at higher risk of developing more severe diarrheal episodes, including persistent diarrhea. At that moment, the recommendation was to use zinc associated with Oral Rehydration Therapy for all children younger than 5 years old (Lamberti etal.,2013).
In 2004, the WHO and UNICEF brought attention to the impact of zinc in reducing the severity of the diarrheal episode and the number of subsequent ADD episodes in children younger than 5 years (WHO/UNICEF,2004).

Zinc is the intrinsic metal component or activating cofactor for more than 70 important enzyme systems, including carbonic anhydrase, the alkaline phosphatases, dehydrogenases, and carboxypeptidases. It is involved in the regulation of nucleoproteins and the activity of various inflammatory cells and plays a role in growth, tissue repair and wound healing, carbohydrate tolerance, and synthesis of testicular hormones. The highest concentrations of zinc in the body are found in the liver, pancreas, kidney, bone, muscles and eyes( Steven etal.,2015)

Zinc deficiency is associated with an increased risk of gastrointestinal infections, adverse effects on the structure and function of the gastrointestinal tract, and impaired immune function. Dietary deficiency of zinc is especially common in low-income countries because of a low dietary intake of zinc-rich foods (mainly foods of animal origin) or inadequate absorption caused by its binding to dietary fiber and phytates often found in cereals, nuts and legumes (Haider and Bhutta.,2009).

Acute zinc deficiency causes a decrease in innate and adaptive immunity, chronic deficiency increases the production of inflammatory cytokines, influencing the outcome of a large number of inflammatory diseases( Bonaventura etal., 2015).

Research in children suggests that zinc supplementation ( $20 \mathrm{mg}$ per day for 10 days 
in children older than two months) may play a crucial role in treating and preventing acute diarrhea, particularly in developing countries. Studies demonstrate a decrease in the risk of dehydration, and in the duration and severity of the diarrheal episode by an estimated $20 \%$ to $40 \%$ ( Bhutta etal.,2000).

\section{AIM OF WORK}

Our aim of work is to determine the role of Zinc as a risk factor in the development of acute diarrhea in children.

\section{Patients and methods}

This case-control study was conducted in the outpatient clinic of Children's Hospital, Fayoum University, Egypt between February and September 2016. It included 90 children diagnosed as acute diarrhea and 80 children of matching age and sex as a control group.

\section{Inclusion criteria:}

1-Patients diagnosed as acute Diarrhea.

2- Age from 6months-6years old.

3- Both sexes.

4- Infective diarrhea either bacterial or viral in origin.

\section{Exclusion criteria:}

1 -patients with chronic diarrhea (diarrhea persisted more than 2 weeks).

2 -Patients taking zinc therapy or drugs that interfere with zinc absorption.

3 -Patients with chronic debiliting disease and chronic malabsorption disorders.
In our study we considered acute diarrhea, according to WHO definition (i.e. the passage of three or more loose or liquid stools per day or more frequently than is normal for the individual for less than 2 weeks duration).

\section{All patients were subjected to;}

1-Full history taking focusing on

- Duration, frequency, character of diarrhea and repeated episode.

- Associated symptoms as vomiting, fever and abdominal pain.

- History of drug intake, change type of artificial milk, history of cow milk intake before attack of diarrhea and recent addition of new foods, history of same condition in another member of family (food poisoning).

-History of complications of diarrhea as convulsion, oliguria, abdominal distension and nutritional history in the form of type of feeding, time of weaning.

\section{2- Clinical assessment}

-Full general examination with special emphasis on signs of dehydration, growth parameters and abdominal examination.

\section{Laboratory Investigation}

- Complete blood picture

- Stool analysis 
- $\quad$ Serum Zinc level (for cases and controls)

- $\quad$ Serum electrolyte (for cases only). After fulfilling the inclusion criteria and taking proxy consent, a sample of $8 \mathrm{ml}$ venous blood sample was collected from children diagnosed as acute diarrhea $3 \mathrm{ml}$ from healthy children in sterile tubes.

The blood sample was divided into: $5 \mathrm{ml}$ in plain tubes for serum collection

$3 \mathrm{ml}$ in EDTA tubes for CBC

Plain tubes were incubated in $37 \mathrm{C}$ for 15 minutes then centrifuged at $3000 \mathrm{rpm}$ for 20 minutes at room temperature.

Sera were separated and divided into two aliquots; one for $\mathrm{Na}, \mathrm{K}$ and the other one was stored at- 20 for zinc analysis.

We use AU480 in chemical analysis for $\mathrm{Na}$, K. and Spectrophotometer 5010 for Zinc analysis

\section{Measurement principles}

Zinc forms with 2(5-Brom 2-pyridylazo)5(N-propyl-N sulfo-propylamino).Phenol a red chelating complex

The increase of absorbance was measured and it was proportional to the concentration of total zinc in the sample.

\begin{tabular}{|c|c|c|}
\hline Serum /Plasma & & \\
\hline children & & \\
\hline$<4$ months & $65-137 \mu \mathrm{g} / \mathrm{dl}$ & $10-21 \mu \mathrm{mol} / \mathrm{l}$ \\
\hline 4-12months & $65-130 \mu \mathrm{g} / \mathrm{dl}$ & $10-20 \mu \mathrm{mol} / \mathrm{l}$ \\
\hline 1-5years & $65-118 \mu \mathrm{g} / \mathrm{dl}$ & $10-18 \mu \mathrm{mol} / \mathrm{l}$ \\
\hline 6-9years & $78-105 \mu \mathrm{g} / \mathrm{dl}$ & $12-16 \mu \mathrm{mol} / \mathrm{l}$ \\
\hline 10-13 male & $78-98 \mu \mathrm{g} / \mathrm{dl}$ & $12-15 \mu \mathrm{mol} / \mathrm{l}$ \\
\hline Female & 78-118 $\mu \mathrm{g} / \mathrm{dl}$ & $12-18 \mu \mathrm{mol} / \mathrm{l}$ \\
\hline 14-19 male & $65-118 \mu \mathrm{g} / \mathrm{dl}$ & $10-18 \mu \mathrm{mol} / \mathrm{l}$ \\
\hline Female & $59-98 \mu \mathrm{g} / \mathrm{dl}$ & 9-15 $\mu \mathrm{mol} / 1$ \\
\hline
\end{tabular}

\section{$\underline{\text { Statistical Analysis }}$}

- Data was collected and coded to facilitate data manipulation and double entered into Microsoft Access and data analysis was performed using SPSS software version 18 in windows 7.

- Simple descriptive analysis in the form of numbers and percentages for qualitative data, and arithmetic means as central tendency measurement, standard deviations as measure of dispersion for quantitative parametric data, and inferential statistic test:

\section{- For quantitative parametric data :}

- In-depended student t-Test used to compare measures of two independent groups of quantitative data

\section{EXPECTED VALUES}


- One way ANOVA test in comparing more than two independent groups of quantitative data.

\section{- $\quad$ For qualitative data}

- Chi square test to compare two of more than two qualitative groups.

- Bivariate Pearson correlation test to test association between variables

- The level $\boldsymbol{P} \leq \mathbf{0 . 0 5}$ was considered the cut-off value for significance.

\section{Ethical Consideration:}

This study was reviewed by the Faculty of Medicine Research Ethical Committee. The participants were informed by the researcher about the objectives of the study, the examination, investigation that was done. Also the confidentiality of their information was respected and their right not to participate in the study was ensured.

\section{Discussion}

Zinc is one of the most important essential trace metals of human nutrition and its deficiency is a world nutritional problem. This work compiles information about the serum level of zinc in diarrhea.

Diarrhea remains the second leading cause of death among children under 5 years in the developing world (Bryce etal., 2006).
WHO found that the percentage of underfour years deaths due to diarrhea in Egypt was 5\% from all causes of death in 2015 , prematurity $24 \%$, congenital anomalies $21.1 \%$, lower respiratory tract infection $12.7 \%$, birth trauma10.7\% , noncommunicable disease $8.5 \%$,perinatal and nutritional cause $7.3 \%$, injures $5.7 \%$, sepsis and other infection $2.9 \%$, tetanus $0.9 \%$, meningitis and encephalitis $0.5 \%$, pertussis $0.6 \%$ and measles $0.2 \%$ (WHO, 2015).

We studied 90 patients with acute diarrhea! their mean age was $27.2 \pm 23.6$ months ranged between 6 and 72 months. Females were $52.9 \%$ of our patients, $62.2 \%$ of the mothers were educated and $37.8 \%$ were illiterate. As regards the residence $62.2 \%$ were from rural areas. The majority of our patients $86.7 \%$ had pipe sewage disposal.

Prevalence of diarrhea by Egypt Demographic and health survey in 2005, 2008 and 2014, found that $19.1 \%$ of ill children with diarrhea were from rural areas in $2005,8 \%$ in 2008 and in 2014 were 14.9\%. Also found that illiterate mothers were $19.5 \%$ in 2005, 7.5\% in 2008 and increased again to $16.4 \%$ in 2014. 
In our study, the mean body weight was $8.3 \pm 2.1 \mathrm{~kg}$, the mean height was $65.8 \pm 6.3$ $\mathrm{cm}$ and the mean head circumference was $42.6 \pm 1.9 \mathrm{~cm}$.

The majority of our cases $(61.1 \%)$ were between the $10^{\text {th }}-90^{\text {th }}$ percentiles for weight, $28.3 \%$ were $\leq 5^{\text {th }}$ percentile in head circumference and $42.3 \% \leq 5^{\text {th }}$ percentile for height.

Height-for-age, a measure of nutritional stunting, is the best known and easiest to measure of the adverse outcomes associated with zinc deficiency in populations. Stunting prevalence is expressed as the percentage of children under 5 years of age with heightfor-age below the expected range of a reference population (i.e., <2.0 standard deviations with respect to the reference median) (Brown etal., 2004).

WHO considers a prevalence of stunting greater than $20 \%$ of the population indicates a public health concern. Although zinc deficiency is not the only factor affecting children's growth, assessment of dietary zinc intake and serum zinc levels can be used to confirm the risk of zinc deficiency in these high-risk countries (Brown etal., 2004).

The etiology of stunting includes the following: (1) Nutritional (energy, macronutrients, micronutrients and toxic factors) (2) Infection (injury to gastrointestinal mucosa, systemic effects and immune stimulation) and 3) Motherinfant interaction (maternal nutrition and stores at birth, and behavioral interactions (Nazanin etal., 2013).

Poverty, poor food choices, lack of availability or decreased accessibility to certain foods, coupled with the lack of knowledge about the importance of food group diversity for the health and growth of young children may limit the inclusion of micronutrient-rich foods in the diets of children. Deficiencies of iron, iodine, zinc, and vitamins $\mathrm{A}$ and $\mathrm{B}-12$ are a major concern among children globally (Krebs, 2007).

In our study there was no statistically significant correlation between serum zinc level and anthropometric measures. A study in Sultan Qaboos University found that serum zinc was not affected by age, weight, height or head circumference (Abolfazl etal., 2015).Also in another study in Iran, they found that the mean serum zinc concentrations were significantly lower among those with lengths less than the fifth percentile for age than among those with 
lengths greater than the fifth percentile for age (Conrad etal., 2010).

In addition the study in Sultan Qaboos University found that children with acute bloody diarrhea had significantly lower serum zinc levels in comparison with healthy children. Additionally, hypozincaemia was observed in half of the children with acute bloody diarrhea and some of those with acute watery diarrhea while none of the control group had hypozincaemia. This reduction in serum zinc levels may be related to either the excretion of zinc following acute diarrhea or metabolic reactions against the infections (known as acute phase responses) or both (Abolfazl etal ., 2015).

In our study there was no statistically significant difference in serum zinc level between cases and controls. Similarly, a study in Iran showed a normal range of serum zinc level among cases with acute diarrhea and controls (Elham etal., 2015).But in India, compared to healthy controls, serum zinc level was higher among ill children with diarrhea (Arora etal.,2006).

In our study we found that there was no statistically significant difference in serum zinc level between males and females, Abolfazl etal.,( 2015) also found no difference in zinc level between males and females, in contrast a study in Shahed University Iran ,Chomeili etal., (2004) found in their study that girls had lower serum zinc level than boys.

Also a study in Turkey showed that serum zinc levels were not affected by gender and age (Akgüin etal., 2007).

In our study there was no statistically significant difference in serum zinc level and different types of feeding, in contrast another study showed that the children who were fed breast milk had higher serum zinc level than those formula fed (Chomeili etal., 2004).

Vomiting was the main presenting symptom associated with diarrhea found in 70 children $(77.8 \%)$, followed by abdominal pain in $63(70 \%)$ and fever in 58 of them $(64.4 \%)$. There was no association between serum zinc level and the symptoms and signs of our cases.A Study of the prevalence of zinc deficiency in Brazil found that the serum zinc level was not changed by symptoms

(Ferraz etal., 2007).

In our study, 29 of our cases (32.1\%) showed signs of dehydration, $26.7 \%$ of them had mild dehydration while $5.6 \%$ had moderate dehydration .None of our patients 
had severe dehydration. There was no statistically significant difference in serum zinc level among patients with and without dehydration level (p-value >0.05). Akgün etal., (2007) found that the serum zinc level of their dehydrated patients $(28 \%$ of their patients)was higher than those with no dehydration.

In our study, serum electrolytes were assayed in children with acute diarrhea. The mean level of serum $\mathrm{Na}$ was $137.3 \pm 2.3$, ranged between 132 and $146 \mathrm{mmol} / \mathrm{l}$, where a high mean serum zinc level was found in children with hyponatremia (P-value $<0.05)$.

The mean serum $\mathrm{K}$ was $4.1 \pm 0.5$ !however there was no statistically significant difference in serum zinc level and different potassium level (with p-value> 0.05).

The character of diarrhea was watery in $98.8 \%$ and $1.1 \%$ had bloody diarrhea. A bacterial cause was suspected in $35.6 \%$ of the cases due to the presence of pus cells (525/ HPF) in stool analysis of 32 children, associated with high total leucocytic count and neutrophilia. RBCs in stool were present in one patient $(1.1 \%)$.

We suspected also a viral cause because some of the cases had watery diarrhea and samples were collected during winter time, but specific investigation weren't done.

Parasitic infestation in the form of oxyuris worms was present in $10 \%$ of our cases and $10 \%$ of the controls.

Parasitic infections are more common in locations where there is unsafe drinking water and poor handling of sewage. Infection with a parasite is uncommon in developed countries but may be seen in children who have recently ingested contaminated water or who have traveled to or lived in developing countries.

It may last for weeks to months. Intestinal protozoan infections by Giardia and Cryptosporidium are common in humans worldwide. Especially important are infections in children, during pregnancy, and among individuals with HIV/AIDS (Savioli etal., 2006).

Amebiasis was the most common protozoal infection found in our cases $(54.4 \%)$ and in $(37.5 \%)$ of the control group. Surveillance for distribution of all enteric infections diarrheal disease in children aged younger than 5 years seeking medical advice at Abu Homos and Manshayet Nasser hospitals from 2005-2007 in Cairo, Egypt found that viruses were $48 \%$,parasites $26 \%$ 
and bacteria in $27 \%$

(El-

Mohamady etal.,2006).

Prevalence and incidence of Entamoeba histolytica infection in South Africa and Egypt showed that Egypt has high rates of asymptomatic infection of ameba detected in the stool (>21\%) (William etal., 2006).

Combined infection with ameba and oxyuris infestations was found in $30 \%$ of our cases and $16.3 \%$ of control groups, whereas Giuardiasis was present in $3.3 \%$ of the cases and $3.5 \%$ of the controls.

Recurrent asymptomatic and symptomatic infections by intestinal parasites among young children can have long-term effects on overall growth and development. A study conducted on children residing in Mexico City

(Long etal., 2007) reported that vitamin $A$ and zinc (20mg of elemental zinc as zinc methionine, daily for 1year) reduced G.lamblia incidence, whereas zinc supplementation alone decreased Entamoeba histolyticaassociated diarrhea.

A study in Iran, found a decrease in serum zinc levels in $50 \%$ of Giardia positive group (Zarebavani etal., 2012).

In our study a high serum zinc level was found in children with normal stool analysis while children with ameabiasis also showed a high mean serum zinc level.

In our study the mean hemoglobin level was $10.5 \pm 0.97(\mathrm{~g} / \mathrm{dl})$, the mean total leucocytic count was10.69 $\pm 2.4\left(\right.$ cells $\left./ \mathrm{m}^{3}\right)$ and the mean platelet count was $320 \pm 66$ $\left(\right.$ cells $\left./ \mathrm{m}^{3}\right)$.

There was statistically significant difference between cases and controls as regards to the hemoglobin level and TLC with most of our cases had low hemoglobin level with most of our cases had low hemoglobin level with low mean corpuscular volume and low mean corpuscular hemoglobin(92.2\% versus $77.5 \%)$ and leukocytosis $(51.1 \%$ versus11.3\%) with $\mathrm{P}$ value respectively 0.009 and $<0.05$.

On the other hand, there was no statically significant difference in platelet count between cases and controls. Information on anemia levels obtained in 2005 by Egypt Demographic and Health Survey showed that the level of anemia among children aged 6-59 months was much higher in 2005 than in 2000 (49\% and 30\%, respectively), and rural children were more likely to be anemic than urban children $(51 \%$ and $44 \%$, respectively); and children in rural Upper Egypt had the highest anemia levels. 
The frequency of anemia in Egypt (as developing countries) is much higher than developed countries, a study in Fayoum University hospital aimed to investigate the prevalence of anemia in Al-Fayom Governorate ( Al Ghwass etal .,2015) and the study in Cairo and El-Minofia found that the frequency of iron deficiency anaemia was $64 \%$ among the studied group. This is higher than other Egyptian studies where the prevalence of iron deficiency anaemia was $43 \%$ and $55 \%$ among studied sample of school children in Cairo and ElMinofia, respectively (Elalfy etal in 2012).

Therefore, it isn't surprising to find a low hemoglobin level with low mean corpuscular volume and low mean corpuscular hemoglobin in $92.2 \%$ of our cases and $77.5 \%$ of the control group.

Pallor was found in ten children of our cases, iron deficiency anemia was found with reduced serum iron, ferritin and total iron binding capacity.

Their mean serum iron was $54.2 \pm 22$ ranged from (31-90) with normal range (100-150 micro gm/dl), the mean serum ferritin was $11.1 \pm 2.7$ ranged from (5-15), with normal range (15-25 nano gm/dl) and the mean TIBC was $512 \pm 341$ ranged from
(159-250) with normal range (250-450 micro gm/dl).

Iron deficiency anemia is the most common micronutrient deficiencyassociated anemia in the world, affecting up to $60 \%$ of children globally .In the United States, the prevalence of anemia (defined as low hemoglobin) continues to be high among children from low-income families, with a prevalence of $15 \%$ for preschoolers (Food and Nutrition Board, Institutes of Medicine ,2005).

A Study in Turkey for serum zinc levels in patients with iron deficiency anemia, showed that serum zinc levels were lower in anemic patients

(Kelkitli etal., 2016).

Micronutrient deficiencies are caused by inadequate dietary intake, increased losses from the body, and/or increased requirements .Zinc and iron usually occur together in food sources. Foods with a high content of dietary zinc and iron include oysters, beef, turkey 'chicken, fortified cereals, and processed bean

(Us Department of Agriculture, 20011).

However, the bioavailability of micronutrients is less than anticipated despite the substantial quantities found in some of these foods (Avalos etal., 
2004),certain components of cereals and legumes, such as phytic acid, fiber, and calcium, affect zinc and iron absorption (Hambidge etal., 2008)

In our study, the mean serum zinc level was91.9 $\pm 18.5 \mu \mathrm{g} / \mathrm{dl}$ in the normal range, also there was no correlation between serum zinc level and frequency of diarrhea, hemoglobin level, sodium level and potassium level.

Many studies have reported contradictory results on the effect of zinc in the treatment of acute diarrhea. A study of 3-59 month old children affected with acute diarrhea in Bangladesh indicated that the daily administration of $20 \mathrm{mg}$ of zinc reduced the duration and frequency of diarrhea (Baqui etal., 2002).

Also another study in Brazil, found that the administration of zinc reduced the duration of diarrhea among Brazilian children $<5$ years old (Al-Sonboli etal.,2003).

Zinc supplementation enhances serum zinc concentration when given as a treatment for diarrhea and helps children maintain a more adequate zinc status during the convalescent period (Baqui etal., 2006).

A study by Bahl etal., (2002) in India, revealed that the administration of zinc along with ORS reduced the severity of acute diarrhea among children between 635 months old In contrast, Patel etal.,(2005) demonstrated that the administration of zinc did not affect the duration of or rate of complications arising from acute diarrhea among children aged 6-59 months receiving either ORS and zinc or ORS and a placebo. The researchers suggested that the inefficacy of zinc in their study may have been attributable to a low dose of zinc, poor compliance and the failure of the supplements to replenish the zinc loss. Other studies have confirmed these results (Long etal., 2006) .

The main limitation of our study is the limited number of patients and lack of studying the effect of zinc administration in the course of diarrhea.

\section{Conclusion:}

Serum zinc level was found normal in children with acute diarrhea as well as the control group and it did not correlate with the frequency of diarrhea, degree of dehydration, hemoglobin level, serum $\mathrm{Na}$ level and serum $\mathrm{K}$.

\section{Recommendations:}

1-Stunting is an important health problem that needs to be addressed by improving nutrition of infants and children.

2-Health education programs should focus on rural areas to improve their environment. 
3-Amoebiasis and parasitic GIT infections are endemic in Egyptian children and should be properly treated.

4- Anemia is prevalent in Egyptian children; we should increase knowledge and accessibility to proper food choices.

5-Improve hygiene to reduce the risk of acute diarrhea by hand washing with soap and water.

6-Zinc is an important micronutrient trace element in the body that is unlikely to be deficient in children with acute diarrhea .However studies with large numbers of patients are needed to elucidate the specific role of zinc in children with diarrhea.

\section{References}

- Abolfazl Mahyar, Parviz Ayazi, Victoria Chegini, Mehdi Sahmani , Sonia

Oveisi, and Shiva Esmaeily(2015): Serum Zinc Concentrations in Children with Acute Bloody and Watery Diarrhea Sultan Qaboos Univ Med J. Nov; 15(4): e512-e516.

- AKGÜN ÖLMEZ, S. SONGÜL YALÇIN, KADRIYE YURDAKÖK and TURGAY COSKUN (2007): Serum zinc levels in children with acute gastroenteritis.

- Al -Ghwass MM, Halawa EF, Sabry SM and Ahmed D (2015): Iron deficiency anemia in an Egyptian pediatric population: a cross-sectional study. Jan-Mar; 14(1):2531. doi: 10.4103/1596-3519.148725.
-Al-Sonboli N, Gurgel RQ, Shenkin A, Hart CA and Cuevas LE (2003): Zinc supplementation in Brazilian children with acute diarrhoea. Ann Trop Paediatr; 23:3-8.

-Arora .R, Kulshreshtha S. , Mohan G., Singh .M and Sharma .P (2006): Estimation of serum zinc and copper in children with acute diarrhea; Biological Trace Elemental Research Volume 114, Issue 1, pp 121-126.

-Assis A.S., Valle D.A., Antunes G.R., Tibiriça S.H., Assis R.M. and Leite J.P (2013): Rotavirus epidemiology before and after vaccine introduction J Pediatr (Rio J), 89: 470476.

-AvalosMishaan AM, Zavaleta N, Griffin IJ, Hilmers DC, Hawthorne KM

and Abrams SA (2004): Bioavailability of iron and zinc from a multiple micronutrient-fortified beverage. J Pediatr; 145:26-31.

-Baqui AH, Black RE, El Arifeen S, Yunus M, Chakraborty J, Ahmed S and etal (2002): Effect of zinc supplementation started during diarrhoea on morbidity and mortality in Bangladeshi children: Community randomised trial. BMJ; 325:1059. doi: 10.1136/bmj.325.7372.1059

-Baqui AH, Black RE, Fischer Walker CL, Arifeen S, Zaman K, Yunus M, Wahed MA and Caulfield LE.(2006): Zinc supplementation and serum zinc during diarrhea Indian J Pediatr Jun;73(6):493-7. 
-Bahl R, Bhandari N, Saksena M, Strand T, Kumar GT, Bhan MK and etal(2002):

Efficacy of zinc-fortified oral rehydration solution in 6- to 35-month-old children with acute diarrhea. J Pediatr. ; 141:677-82. doi: 10.1067/mpd.2002.128543.

-Bhutta ZA., Bird SM. and Black RE. (2000): Therapeutic effects of oral zinc in acute and persistent diarrhea in children in developing countries: pooled analysis of randomized controlled trials. Am J Clin Nutr; 72(6):1516-1522.

- Bonaventura P., Benedetti G., Albarède F. and Miossec P (2015): Zinc and its role in immunity and inflammation. Autoimmun Rev.; 14:277-285.

-Boschi-Pinto Cynthia, Lana Velebit,b and Kenji Shibuyac(2008): Estimating child mortality due to diarrhea in developing countries Sep; 86(9): 710-717. doi: 10.2471/BLT.07.050054

\footnotetext{
-Brown KH, Rivera JA, Bhutta Z, Gibson RS, King JC and etal (2004): Assessment of the risk of zinc deficiency in populations and options for its control. International Zinc Nutrition Consultative Group (IZINCG) technical document, Food Nutr Bull.; 25:S99-203.
}

- Bryce J., Boschi-Pinto C., Shibuya K.and Black RE.(2005): WHO estimates of the causes of death in children; 365(9465):1147-52.

- Bryce J, Boschi-Pinto C, Shibuya K and Black RE (2006): WHO Child Health Epidemiology Reference Group. WHO estimates of the causes of death in children Lancet 2005; 365:1147-1152.glected Diseases Initiative' Trends Parasitol; 22:203-208.

- Chomeili B, Badvi M, Moosavi SA and Kholdi N (2004): The relationship between level of serum zinc and acute diarrhea in children. Daneshvar Medicine. April- May; 11(50):13-20.

- Conrad R Cole, Frederick K Grant, E Dawn Swaby-Ellis, Joy L Smith, Anne Jacques, Christine A NorthropClewes, Kathleen L Caldwell, Christine M Pfeiffer, and Thomas R Ziegler(2010): Zinc and iron deficiency and their interrelations in lowincome African American and Hispanic children in Atlanta1,2,3,4 American Society for Nutrition.

- Egypt Demographic and Health Survey (2015):

Children in Egypt Prevalence of diarrhea: Proportion of under-five children ill with diarrhea,2005-2014.

- Elalfy MS, Hamdy AM, Maksoud SS and Megeed RI (2012): Pattern of milk feeding and family size as risk factors for iron deficiency anemia among poor Egyptian infants 6 to 24 months old.

Nutr Res; 32:93-9. 
- Elham Talachian, Ali Bidari, Samileh Noorbakhsh, Azardokht Tabatabaei, and Fereshteh Salari (2015): Serum levels of vitamins $\mathrm{A}$ and $\mathrm{D}$, and zinc in children with acute diarrhea: A cross-sectional study; 29: 207.

- El-Mohamady H, Abdel-Messih IA, Youssef FG, Said M, Farag H, Shaheen HI, Rockabrand DM, Luby SB, Hajjeh R, Sanders JW, Monteville MR, Klena JD and Frenck RW (2006): Enteric pathogens associated with diarrhea in children in Fayoum, Egypt. Diagn Microbiol Infect Dis 56: 1-5.

- Ferraz IS, Daneluzzi JC, Vannucchi H, Jordão Jr AA, Ricco RG, Del Ciampo LA, Martinelli CE Jr, Engelberg AA, Bonilha LR and Custódio VI(2007):zinc serum levels and their association with vitamin A deficiency in preschool children:83(6):512-7

- Food and Nutrition Board, Institutes of Medicine (2005): Dietary Reference Intakes For Energy, Carbohydrate, Fiber, Fat, Fatty Acids, Cholesterol, Protein, and Amino Acids.

- Haider BA. And Bhutta ZA. (2009): The effect of therapeutic zinc supplementation among young children with selected infections: a review of the evidence Food and Nutrition Bulletin; 30(Suppl. 1):S41-59.
- Hambidge KM, Miller LV, Westcott JE and Krebs NF (2008): Dietary reference intakes for zinc may require adjustment for phytate intake based upon model predictions. J Nutr ; 138:2363-6.

- Kelkitli E, Ozturk N, Aslan NA, Kilic-Baygutalp N, Bayraktutan Z, Kurt N, Bakan N and Bakan E (2016): Serum zinc levels in patients with iron deficiency anemia and its association with symptoms of iron deficiency anemia. 95(5):751-6. doi: 10.1007/s00277-016-2628-8. Epub

- Krebs NF (2007): Food choices to meet nutritional needs of breast-fed infants and toddlers on mixed diets. J Nutr; 137:511S-7S.

- Lamberti L.M., Walker C.L., Jian and Wand Black R.E (2013): oral zinc supplementation for the treatment of acute diarrhea in children: a systematic review and meta-analysis; Nutrients; 5 ,pp. 47154740.

\section{- Long KZ, Montoya Y, Hertzmark E, Santos JI} and Rosado JL (2006): A double-blind, randomized, clinical trial of the effect of vitamin A and zinc supplementation on diarrheal disease and respiratory tract infections in children in Mexico City, Mexico. Am J Clin Nutr. ; 83:693-700.

- Long KZ, Rosado JL, Montoya Y and etal (2007): Effect of vitamin A and zinc supplementation on gastrointestinal parasitic infections among Mexican children.Pediatrics; 120:e846-e855.

- Mathers CD., Ezzati M., Lopez AD. (2007): Measuring the burden of neglected tropical diseases: 
the global burden of disease framework; PLoS (WHO) (2009): Diarrhea why children are still

Neglected Tropical Diseases.; 1(2):e114.

- Nazanin Roohani, Richard Hurrell, Roya

Kelishadi, and Rainer Schulin (2013): Zinc and its importance for human health: An integrative review18(2): 144-157.

- Patel AB, Dhande LA and Rawat MS

(2005): Therapeutic evaluation of zinc and copper supplementation in acute diarrhea in children: double blind randomized trial. May; 42(5):433-42.

- Savioli L, Smith H, and Thompson .A (2006): Giardia and Cryptosporidium join the 'Neglected Diseases Initiative'.

- Steven A Abrams., Kathleen J. and Alison G. (2015): Zinc deficiency and supplementation in children and adolescents: 130-1378S.

- United Nations Children's Fund (UNICEF)/World Health Organization dying and what can be done. Geneva

- $\quad$ US Department of Agriculture (2011):

Agricultural Research Service. USDA nutrient database for standard reference

- William Stauffer, Mohamed Abd-Alla and

Jonathan I. Ravdin(2006): Prevalence and Incidence of Entamoeba histolytica Infection in South Africa and Egypt Volume 37, Issue 2, Pages 265-268.

- World Health Organization and United Nations Children's Fund (2004): Clinical management of acute diarrhea (WHO/UNICEF).

- World Health Organization(2015):estimate of child cause of death

- Zarebavani M, Dargahi D, Einollahi N, Dashti N, Mohebali M and Rezaeian M (2012): Serum Levels of Zinc, Copper, Vitamin B12, Folate and Immunoglobulin in Individuals with Giardiasis 41(12): 47-53. 